\title{
BMJ Open Initiation and completion rates of isoniazid preventive therapy among people living with HIV in Far-Western Region of Nepal: a retrospective cohort study
}

\author{
Govinda Prasad Dhungana, ${ }^{1}$ Pruthu Thekkur, ${ }^{2,3}$ Palanivel Chinnakali, ${ }^{4}$ \\ Usha Bhatta, ${ }^{5}$ Basudev Pandey, ${ }^{6}$ Wei-Hong Zhang ${ }^{7,8}$
}

To cite: Dhungana GP,

Thekkur P, Chinnakali P, et al. Initiation and completion rates of isoniazid preventive therapy among people living with HIV in Far-Western Region of Nepal: a retrospective cohort study. BMJ Open 2019;9:e029058. doi:10.1136/ bmjopen-2019-029058

- Prepublication history and additional material for this paper are available online. To view these files, please visit the journal online (http://dx.doi org/10.1136/bmjopen-2019029058).

Received 10 January 2019 Revised 28 March 2019 Accepted 30 April 2019
D) Check for updates

(c) Author(s) (or their employer(s)) 2019. Re-use permitted under CC BY-NC. No commercial re-use. See rights and permissions. Published by BMJ.

For numbered affiliations see end of article.

\section{Correspondence to} Govinda Prasad Dhungana; dhunganagovinda7826@yahoo. com

\section{ABSTRACT}

Objectives Isoniazid preventive therapy (IPT), for people living with HIV (PLHIV) is the proven and recommended intervention to avert tuberculosis (TB). In 2015, Nepal implemented 6 months of IPT for all PLHIV registered for HIV care in antiretroviral therapy (ART) centres. After programmatic implementation, there has been no systematic assessment of IPT initiation and completion rates among PLHIV. We aimed to assess IPT initiation and completion rates in the Far-Western Region (FWR) of Nepal.

Design We conducted a retrospective cohort study using secondary data extracted from registers maintained at ART centres.

Setting All 11 ART centres in the FWR of Nepal.

Participants All PLHIV registered for care between January 2016 and December 2017 in 11 ART centres.

Primary outcome measures IPT initiation and completion rates were summarised as percentages with $95 \% \mathrm{Cl}$. Independent association between patient characteristics and non-initiation of IPT was assessed using cluster-adjusted generalised linear model (log binomial regression) and adjusted relative risk (RR) with $95 \% \mathrm{Cl}$ was calculated.

Result Of the 492 PLHIV included, 477 (97.0\%) did not have active TB at registration. Among 477 without active TB, 141 $(29.8 \%, 95 \% \mathrm{Cl} 25.7 \%$ to $34.1 \%)$ had been initiated on IPT and $85(17.8 \%)$ were initiated within 3 months of registration. Of 141 initiated on IPT, $133(94.3 \%, 95 \% \mathrm{Cl} 89.1 \%$ to $97.5 \%)$ had completed 6 months of IPT. Being more than 60 years of age (RR-1.3, 95\% Cl 1.1 to 1.7), migrant worker (RR-1.3, 95\% Cl 1.1 to 1.4 ) and not being initiated on ART (RR-1.4, $95 \% \mathrm{Cl} 1.1$ to 1.8) were significantly associated with IPT initiation.

Conclusions In FWR of Nepal, three out of 10 eligible PLHIV had received IPT. Among those who have received IPT, the completion rate was good. The HIV care programme needs to explore the potential reasons for this low coverage and take context specific corrective action to fix this gap.

\section{INTRODUCTION}

Tuberculosis (TB) is the leading cause of mortality among people living with HIV (PLHIV). ${ }^{1}$ Globally, around $400 \quad 000$ TB related deaths occurred among PLHIV in

\section{Strengths and limitations of this study}

- First study from resource limited Far-Western Region of Nepal on isoniazid preventive therapy (IPT) implementation.

- Minimal scope for selection bias as all the people living with HIV (PLHIV) registered for care in the 11 antiretroviral therapy centres in the region were included.

- Study was conducted in programmatic setting and $10 \%$ of data extraction forms were validated by principal investigator.

- Use of secondary data with potential documentation errors and incompleteness.

- Possibility of overestimation of the proportion eligible for IPT, as all PLHIV without active tuberculosis were considered as eligible for IPT.

2017, accounting for about one-third of all-cause mortality. ${ }^{1}$ Prevention, early diagnosis and treatment of TB can therefore help avert significant number of deaths among PLHIV.

In 2008, to decrease the TB burden among PLHIV, the WHO recommended 'Three I's strategy' consisting of three interventions: (i) intensified $\mathrm{TB}$ case finding and linkage to high-quality anti-TB treatment (ii) TB prevention using isoniazid preventive therapy (IPT) and early antiretroviral therapy (ART), irrespective of $\mathrm{CD} 4$ count and clinical staging and (iii) infection control in HIV care facilities and other congregate settings. ${ }^{3-5}$

Early initiation of ART is a standalone intervention to reduce TB incidence among PLHIV and TB burden in countries with high prevalence of HIV. ${ }^{6-11}$ Since most countries have adopted 'test and treat' strategy for PLHIV, ART coverage has improved with around 21.7 million PLHIV on ART in 2017. ${ }^{2}$ 
Though ART reduces the risk of TB among PLHIV, ART alone may not be enough to bring down the risk of developing TB among PLHIV to that of HIV negative individuals. ${ }^{12}{ }^{13}$ Hence, there is a evidence based need for interventions like IPT to complement the effect of ART.

IPT for 6 or 36 months has proven to be beneficial in reducing the risk of TB in both adults and children. ${ }^{14-16}$ Studies have reported that IPT and ART have a synergistic effect in reducing the burden of TB and mortality among PLHIV. ${ }^{17-21}$ Although the WHO recommended IPT for PLHIV in 2004, majority of the countries did not implement IPT in their HIV care programme. ${ }^{22}$ Globally, only about $42 \%$ of all the newly diagnosed PLHIV were started on IPT in 2016. ${ }^{1}$ Also, studies have reported varied IPT completion rates ranging from $64 \%$ to $96 \%{ }^{23-28}$

Nepal, a landlocked country in South Asia, is experiencing a concentrated HIV epidemic with an overall estimated prevalence of $0.3 \%$. Nepal has substantial TB burden with estimated 45000 new TB patients (incidence rate of 152 per 100000 population) and 6900 deaths due to TB in 2017. ${ }^{1}$ In Nepal, TB is ranked as the sixth leading cause of death and is thus considered as a major public health problem. ${ }^{29}$

In 2012, sentinel surveillance estimated high prevalence $(11 \%)$ of TB among PLHIV. ${ }^{30}$ In the wake of this, the National Centre for AIDS and Sexually Transmitted Disease Control (NCASC) and National TB Centre (NTC) jointly implemented IPT as a pilot programme in five ART centres located in tertiary care hospitals in December 2012. Operational research conducted during this pilot phase reported low IPT initiation rate $(32 \%)$ but high completion rate $(87 \%) .{ }^{27}$ In December 2015 , IPT for PLHIV was scaled up to all ART centres in the country. However, there has been no evaluation of IPT coverage and completion rates after programmatic implementation of IPT in Nepal.

Far-Western Region (FWR, also known as Province seven) of Nepal is an under developed region with highest prevalence of job-related outward migration. ${ }^{31}$ The region has low literacy and high poverty levels. ${ }^{31}$ There is anecdotal evidence that TB/HIV care provision is complicated in the region due to poor healthcare facilities and outward migration leading to attrition from care.

Though IPT has been implemented in the ART centres of the FWR of Nepal since January 2016, no concurrent evaluations have been conducted to assess the coverage and completion rates of IPT. There is an anecdotal evidence of poor IPT coverage in the region. Systematic assessment of IPT coverage and completion rates will help the programme managers to revisit the strategies adopted and take corrective actions. Therefore, this study was planned to assess the IPT coverage and completion rate, and to identify key sociodemographic and baseline clinical characteristics associated with non-initiation of IPT.

\section{METHODOLOGY}

\section{Study design}

A cohort study was conducted using secondary data collected routinely by the National HIV programme.

\section{Study setting}

\section{General setting}

This study was carried out in the ART centres of FWR of Nepal. The FWR is one of the five developmental regions of the Nepal; Eastern, Central, Western, Mid-Western and Far-Western Region. The region has nine districts and a population of around 2.5 million. ${ }^{32}$ The region has poor health indicators, high prevalence of poverty $(40 \%)$ and low literacy rate $(30 \%) .{ }^{33}$ Due to lack of job opportunities and poverty in the region, there is job-related migration to cities of Nepal and India. With concentrated epidemic among the outward migrants, the region has relatively higher estimated HIV prevalence $(0.4 \%)$ compared with the national estimate $(0.3 \%))^{34}$

\section{Specific setting}

There are 11 ART centres in the FWR Region which are colocated with district hospital or tertiary care centres. At least one ART centre is present in each of the nine districts of the region. The NCASC under Ministry of Health and Population provides HIV treatment and care services through these ART centres. All services in these ART centres are provided free of cost.

\section{HIV testing and linking to HIV care in the region}

HIV testing services are provided through 'Voluntary Counselling and Testing centres' (VCTC) located in the secondary level public health facilities. All ART centres also have VCTC facilities. In VCTC, those individuals detected to be seropositive for HIV are counselled and referred to the nearby ART centres for care and treatment. All the laboratory and clinical examination details during registration and follow-up are documented in the ART register maintained at ART centres.

Patients successfully referred to ART centre are registered in the 'ART register' of ART centre with a unique 'ART ID number'. As per 'test and treat' policy, all registered PLHIV are initiated on appropriate ART by the ART medical officer after clinical and laboratory evaluation. ${ }^{35}$ After providing adherence counselling, once-daily fixeddose combination (FDC) drugs are dispensed for 15 days. If the individual is found to be adherent, the drugs are dispensed for a period 1 month.

\section{Isoniazid preventive therapy for PLHIV}

Since 2016, HIV/TB comprehensive package was implemented in the ART centres of the region. All newly registered PLHIV are screened for active TB using the WHO symptom screen and national TB guidelines (cough, excessive night sweat, fever for $>2$ weeks and weight loss of $>3 \mathrm{~kg}$ with in 4 weeks) during their first visit. Individuals with any of the four symptoms are evaluated for TB using sputum smear microscopy and chest radiography. After evaluation, those PLHIV without TB and without known 
liver disease, active alcohol use, prior isoniazid resistance, peripheral neuropathy and unexplained illness are considered eligible to receive IPT and IPT should be dispensed to them by the ART medical officer.

PLHIV who are eligible for IPT receive isoniazid (300 mg for adults and $200 \mathrm{mg}$ for children) and pyridoxine ( $25 \mathrm{mg}$ ) for 6 months. The IPT drugs are dispensed along with ART drugs during monthly visit to ART centre. IPT is stopped in case PLHIV develops active TB or severe adverse drug events. The details of the drugs dispensed, adverse drug reaction and completion of the IPT are recorded in 'IPT register' maintained at ART centres.

\section{Study population}

PLHIV registered in ART centres of FWR, Nepal during January 2016 to December 2017 were eligible for the study. The minimum sample size was calculated to be 204, assuming percentage of IPT initiation to be $32 \%,{ }^{27}$ relative precision of $20 \%$ and $95 \%$ CI. However, we included all PLHIV registered during the reference period.

\section{Data variables, sources of data and data collection}

Data variables like ART ID number, age, gender, marital status, education, occupation, mode of HIV transmission, tobacco use, alcohol use, date of registration at ART centre, date of HIV testing, WHO clinical staging at baseline, $\mathrm{CD} 4$ count, ART start date, ART regimen, TB disease during registration, liver disease at registration, neuropathy at registration, severe illness at registration and date of IPT initiation were extracted from the 'ART register'. The outcome variables like IPT status, IPT completion, date of IPT completion and reasons for non-completion were extracted from the 'IPT register'. Self-designed data collection proforma was used to extract details from the registers.

Six trained 'data collectors' extracted data during JuneAugust 2018. The principal investigator visited each ART centre at least once during the data collection period and verified at least $10 \%$ of the proformas filled by each 'data collector' for quality and completeness.

\section{Operational definition}

IPT eligible: PLHIV without active TB or not diagnosed with TB within 3 months of ART registration in whom there is no documented evidence of liver disease, active alcohol use, jaundice, prior isoniazid resistance, peripheral neuropathy and unexplained illness in the 'ART register' during initial assessment.

IPT initiation: IPT is said to be initiated when the eligible PLHIV receives IPT after eligibility assessment.

IPT completion: The IPT is said to be completed if the individual started on IPT receives it during six consecutive visits to ART centre and is indicated as 'IPT completed' in 'IPT register'.

\section{Data entry and analysis}

Data were double entered and validated using EpiData V.3.1 entry software. Data were analysed using Stata V.12.0 software. Categorical variables like IPT eligibility, IPT initiation, IPT initiation within 3 months and IPT completion were summarised as percentages with $95 \%$ CI.

The association between sociodemographic and baseline clinical characteristics with not initiating of IPT was assessed using bivariate log binomial regression. Unadjusted relative risk (RR) with 95\% CI was calculated as measure of association. To assess the independent association, a cluster (ART centre) adjusted generalised linear model (Poisson regression) with variables having $\mathrm{p}$ value $<0.25$ in the univariate $\log$ binomial regression was developed. Adjusted RR with 95\% CI was calculated. Quantitative variables like age and CD4 level were classified into appropriate class intervals prior to calculating adjusted RR with $95 \%$ CI.

\section{Sensitivity analysis}

In the current study, except for details of TB symptom screening and diagnosis of TB, none of the other details on IPT eligibility criteria (liver disease, active alcohol use, jaundice, prior isoniazid resistance, peripheral neuropathy and unexplained illness) were documented in the 'ART registers'. Hence, only those with active TB could be considered as not eligible for IPT. Sensitivity analysis was conducted to accommodate for potential deficiency in documentation of IPT eligibility examination results.

\section{Patient and public involvement}

Principal investigator and the data collectors did not interact directly with the PLHIV registered for care in the ART centres during this retrospective record review. The investigators interacted with the ART centre in-charge, counsellors and peer educators of all the ART centres included in the study. Findings from this study will help the national TB programme and NCASC programme of Nepal to identify the gaps in IPT implementation and eventually improve the care and treatment of PLHIV.

\section{RESULTS}

Between January 2016 and December 2017, a total of 492 PLHIV had been registered at ART centres of FWR, Nepal. Of 492 PLHIV, 267 (54\%) were male and the mean (SD) age was $36^{14}$ years. Sociodemographic and clinical characteristics are described in table 1 . Of total, $8 \%$ were children (0-14 years) and $3 \%$ were elderly ( $\geq 60$ years). At the time of registration, $44 \%$ were in WHO clinical staging III or IV. Of total, $98 \%$ were initiated on ART and majority of them $(86 \%)$ were on tenofovir, lamivudine, efavirenz regimen in FDC. The details on education and occupation status were missing for more than $50 \%$ of the study participants.

Of the total 492 PLHIV, 15 (3.0\%) had been diagnosed with active $\mathrm{TB} ; 11$ had $\mathrm{TB}$ at the time of registration and four were diagnosed within 3 months. In total, 477 (97.0\%, 95\% CI 95.0\% to 98.3\%) PLHIV were eligible for IPT. Of 477 PLHIV, 85 (17.8\%, 95\% CI $14.5 \%$ to $21.6 \%)$ were initiated on IPT within 3 months of registration and $56(11.7 \%)$ were initiated later. Median (IQR) duration 
Table 1 Sociodemographic and clinical characteristics of PLHIV registered between January 2016 and December 2017 in the Far-Western Region of Nepal, n=492

\begin{tabular}{|c|c|c|}
\hline Characteristics & Categories & Number (\%) \\
\hline Total & & $492(100)$ \\
\hline \multirow[t]{5}{*}{ Age groups (years) } & $<15$ & $40(8.1)$ \\
\hline & $15-29$ & $89(18.1)$ \\
\hline & $30-44$ & $225(45.7)$ \\
\hline & $45-60$ & $123(25.0)$ \\
\hline & $\geq 60$ & $15(3.0)$ \\
\hline \multirow[t]{3}{*}{ Gender } & Male & $267(54.3)$ \\
\hline & Female & $224(45.5)$ \\
\hline & Others & $1(0.2)$ \\
\hline \multirow[t]{4}{*}{ Education } & Illiterate & 78 (15.9) \\
\hline & Just literate* & $70(14.2)$ \\
\hline & Had formal education & $39(7.9)$ \\
\hline & Not recorded & $305(62.0)$ \\
\hline \multirow[t]{6}{*}{ Occupation } & Unemployed & $20(4.1)$ \\
\hline & Farmer & $10(2.0)$ \\
\hline & Housewife & $87(17.7)$ \\
\hline & Migrant worker & 78 (15.9) \\
\hline & Others & $22(4.5)$ \\
\hline & Not recorded & $275(55.9)$ \\
\hline \multirow[t]{3}{*}{ Marital status } & Married & $380(77.2)$ \\
\hline & Unmarried & $52(10.6)$ \\
\hline & Widow/separated & $60(12.2)$ \\
\hline \multirow[t]{5}{*}{ CD4 count } & Less than 200 & $128(26.0)$ \\
\hline & $201-350$ & $76(15.4)$ \\
\hline & $351-500$ & $76(15.4)$ \\
\hline & More than 500 & $69(14.1)$ \\
\hline & Not recorded & $143(29.1)$ \\
\hline \multirow{3}{*}{$\begin{array}{l}\text { WHO clinical } \\
\text { staging }\end{array}$} & I and II & $276(56.1)$ \\
\hline & III and IV & $183(37.2)$ \\
\hline & Not recorded & $33(6.7)$ \\
\hline \multirow[t]{3}{*}{ ART regimen } & TLE regimen & $421(85.6)$ \\
\hline & Other regimen & 60 (12.2) \\
\hline & Not initiated on ART & $11(2.2)$ \\
\hline
\end{tabular}

${ }^{*}$ Able to read and write but no formal education.

ART, antiretroviral therapy; PLHIV, people living with HIV;

TLE, tenofovir, lamivudine, efavirenz.

between registration and initiation of IPT was 41 (0-198) days. Of 141 initiated on IPT, 133 (94\%, 95\% CI 89.1\% to $97.5 \%$ ) completed 6 months of therapy. Eight patients $(6 \%)$ did not complete IPT; five were lost to follow-up and three discontinued due to adverse drug effects. Eligibility for IPT, IPT initiation and completion rates are described in figure 1 . The IPT initiation rate ranged from

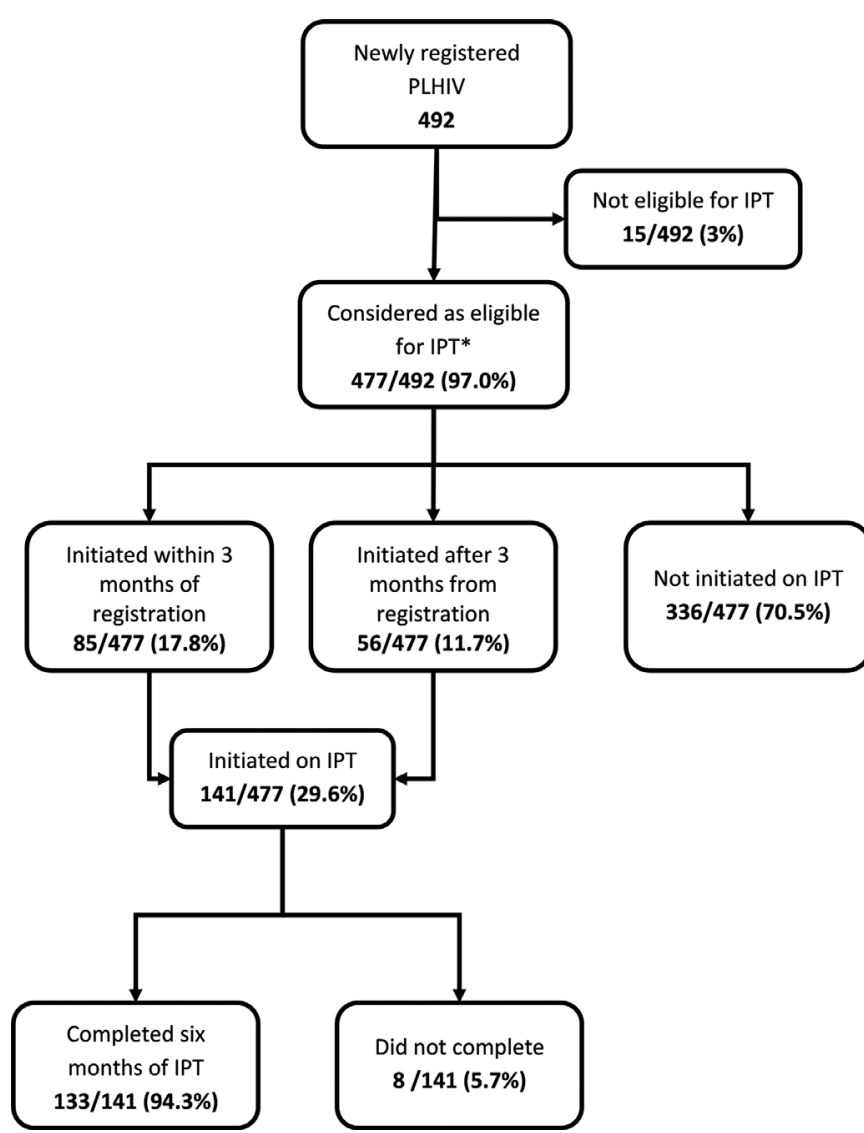

Figure 1 Flow diagram depicting eligibility, initiation and completion of IPT among PLHIV registered between January 2016 and December 2017 in the Far-Western Region of Nepal. *Those without active TB were considered eligible for IPT due to lack of information on liver disease, active alcohol use, jaundice, prior isoniazid resistance, peripheral neuropathy and unexplained illness. IPT, isoniazid preventive therapy; PLHIV, people living with HIV; TB, tuberculosis.

$0 \%$ to $57 \%$ across 11 ART centres (figure 2 and online supplementary table 1 ).

Sociodemographic and clinical characteristics associated with non-initiation of IPT are described in table 2 and table 3. Non-initiation was higher among children $(78 \%)$ and elderly $(83 \%)$ compared with PLHIV aged $45-59$ years $(64 \%)$. Non-initiation rate was higher among migrant workers (82\%). All PLHIV who were not on ART $(n=11)$ had not been initiated on IPT. In adjusted analysis, age more than 60 years (RR-1.3, 95\% CI 1.1 to 1.7 ), migrant worker (RR-1.3, 95\% CI 1.1 to 1.4 ) and non-initiation of ART (RR-1.4, 95\% CI 1.1 to 1.8 ) were independently associated with higher rates of non-initiation of IPT.

\section{Sensitivity analysis}

Considering about $10 \%$ of those without active TB at registration would have been found to be ineligible for IPT, about 431 (87.3\%) would have been eligible for IPT initiation. Considering 141 individuals were started on IPT among those eligible based on sensitivity analysis, the IPT initiation rate would be $32.7 \%$ (141 out of 431 ). 
Map of the ART centers in the Far-Western region, Napal

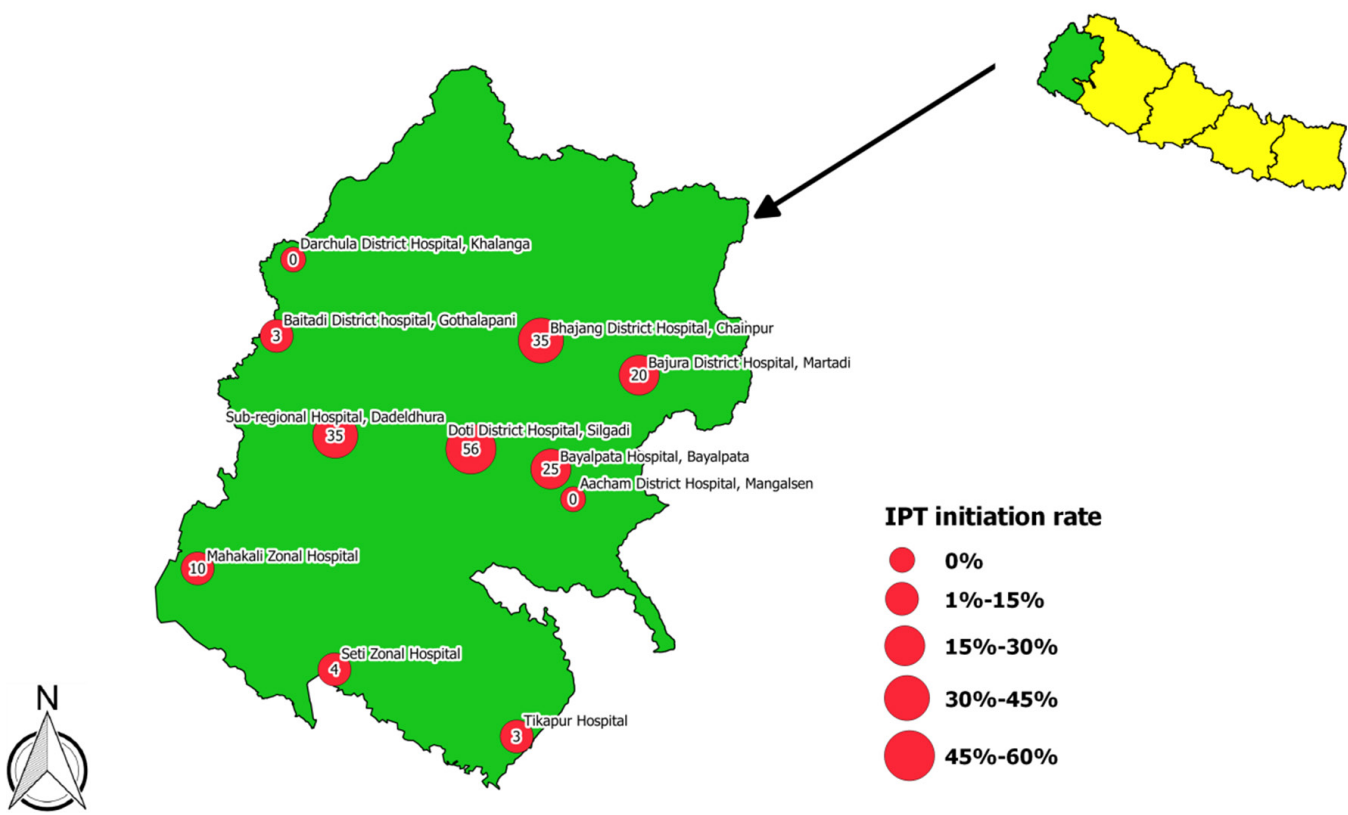

Figure 2 Map depicting the ART centres of the Far-Western Region of Nepal with IPT initiation rate among PLHIV registered between January 2016 and December 2017. Source for Nepal admin shape files is http://diva-gis.org/download which is free and open source. Software used to create figure 2, QGIS (previously known as Quantum GIS), is a free and open source cross platform desktop geographic information system (GIS) application that supports viewing, editing and analysis of geospatial data. ART, antiretroviral therapy; IPT, isoniazid preventive therapy; PLHIV, people living with HIV.

\section{DISCUSSION}

To our knowledge, this is the first study from Nepal assessing the IPT eligibility, initiation and completion rate among PLHIV in the programmatic setting after universalisation of IPT in 2015. Though majority of PLHIV were eligible for IPT, only three out of 10 were initiated on IPT. Among those initiated on IPT, almost all (95\%) completed 6 months of IPT.

In the current study, proportion of PLHIV eligible for IPT $(97 \%)$ was found to be higher than those reported by previous studies. ${ }^{25} 2728$ The study conducted in Kathmandu, Nepal during pilot phase of IPT implementation had reported about $87 \%$ of PLHIV to be eligible for IPT. ${ }^{27}$ This Kathmandu study also had considered all those without active TB as eligible for IPT, similar to the current study. Contrary to our study where a cohort of newly registered patients was included, the previous study was a cross-sectional study and had included PLHIV on care since several years. As risk of TB increases over time and ART initiation rate was low, there might have been relatively higher proportion of active TB patients (13\%) in previous study compared with this study $(3 \%)$.

Similar to our study, a study conducted in Malawi among newly registered PLHIV reported that about $2 \%$ were ineligible for IPT as they had been diagnosed with active TB at registration. ${ }^{25}$ The Malawi study also reported that $9 \%$ were not eligible due to failure to for IPT due to at least one contraindication for initiating IPT. In the current study, except for details of TB symptom screening and diagnosis of TB, none of the other details on IPT eligibility were documented in the 'ART registers'. This might be either due to poor compliance to IPT eligibility testing itself or deficiency in documentation of these examination details.

In the current study, we found the IPT coverage rate $(30 \%)$ to be relatively poor compared with other studies. ${ }^{25} 2836$ The current study had poor IPT coverage even after adjusting for overestimation of IPT eligibility (33\%). ${ }^{25} 28{ }^{36}$ Low IPT coverage may be due to several structural and provider level deficiencies in the FWR of Nepal. The poor infrastructure in health facilities for assessing eligibility, limited manpower, untrained health workforce, poor adherence to guidelines, interrupted drug supply and drug stock-outs, and lack of monitoring on IPT eligibility, initiation and completion rates might have led to low coverage of IPT in FWR of Nepal. The IPT initiation rates varied across the ART centres (0\%-56\%) within FWR indicating that IPT coverage rates are by large dependent on ART centres and therefore, indirectly related to infrastructural and provider capacity of the centre. Also, patient groups like old age, migrant worker and those not initiated on ART had very low coverage of IPT.

The HIV care programme recommends initiating IPT among eligible PLHIV at the time of registration. Even if IPT is not initiated during registration, it needs to be initiated within the next few visits to ART centre. However, only $18 \%$ of the PLHIV were initiated on IPT within 3 months of being eligible at the time of registration. Initiation of IPT after 3 months might not reflect the health system response for IPT eligibility assessment done at the time of registration. Majority of the previous studies were cross-sectional studies and had considered 'ever initiated on IPT' to 
Table 2 Sociodemographic factors associated with non-initiation of IPT among PLHIV registered between January 2016 and December 2017 in the Far-Western Region of Nepal, $\mathrm{n}=477$

\begin{tabular}{|c|c|c|c|c|}
\hline Characteristic & Total, N (\%)* & $\begin{array}{l}\text { Not initiated on IPT, } \\
\mathrm{N}(\%) \dagger\end{array}$ & $\begin{array}{l}\text { Unadjusted RR } \\
(95 \% \mathrm{Cl})\end{array}$ & $\begin{array}{l}\text { Adjusted RR } \\
(95 \% \mathrm{Cl}) \\
\end{array}$ \\
\hline Total & 477 (100) & $336(70.4)$ & & \\
\hline \multicolumn{5}{|l|}{ Age groups (years) } \\
\hline$<15$ & $40(8.4)$ & $31(77.5)$ & 1.2 (1.0 to 1.5$)$ & 1.3 (0.7 to 2.4$)$ \\
\hline $15-29$ & 89 (18.6) & $63(70.8)$ & 1.1 (0.9 to 1.3 ) & 1.1 (0.9 to 1.4$)$ \\
\hline $30-44$ & $221(46.3)$ & $155(70.1)$ & 1.1 (0.9 to 1.3$)$ & 1.1 (0.9 to 1.3$)$ \\
\hline $45-59$ & $98(20.5)$ & $63(64.3)$ & 1 & 1 \\
\hline$\geq 60$ & $29(6.07)$ & $24(82.8)$ & 1.3 (1.0 to 1.6$)$ & 1.3 (1.1 to 1.7$)$ \\
\hline \multicolumn{5}{|l|}{ Gender } \\
\hline Male & $253(53.0)$ & $182(72.0)$ & 1.0 (0.9 to 1.2$)$ & $1.0(0.8$ to 1.1$)$ \\
\hline Female and others & $224(46.9)$ & $154(68.8)$ & 1 & 1 \\
\hline \multicolumn{5}{|l|}{ Education } \\
\hline Illiterate & $78(16.3)$ & 65 (83.3) & 1.2 (0.9 to 1.5$)$ & 1.2 (0.9 to 1.5$)$ \\
\hline Just literate§ & $70(14.7)$ & $54(77.1)$ & 1.1 (0.9 to 1.4$)$ & 1.0 (0.9 to 1.2$)$ \\
\hline Had formal education & $38(8.0)$ & $27(71.1)$ & 1 & 1 \\
\hline Not recorded & 291 (61.0) & $190(65.3)$ & $0.9(0.7$ to 1.1$)$ & 0.9 (0.7 to 1.2$)$ \\
\hline \multicolumn{5}{|l|}{ Occupation } \\
\hline Unemployed & $20(4.2)$ & $16(80.0)$ & 1.1 (0.7 to 1.8$)$ & $1.0(0.8$ to 1.4$)$ \\
\hline Farmer & $10(2.1)$ & $7(70.0)$ & 1 & 1 \\
\hline Housewife & 87 (18.2) & 66 (75.9) & 1.1 (0.7 to 1.7 ) & $1.2(1.0$ to 1.4$)$ \\
\hline Migrant worker & 77 (16.1) & $63(81.8)$ & 1.2 (0.8 to 1.8$)$ & 1.3 (1.1 to 1.4$)$ \\
\hline Others & $22(4.6)$ & $15(68.2)$ & 1.0 (0.6 to 1.6$)$ & 0.9 (0.6 to 1.5$)$ \\
\hline Not recorded & $261(54.7)$ & $169(64.8)$ & 0.9 (0.6 to 1.4$)$ & 1.1 (0.9 to 1.4$)$ \\
\hline \multicolumn{5}{|l|}{ Marital status } \\
\hline Married & 367 (76.9) & $266(72.5)$ & 1.4 (1.1 to 1.7$)$ & 1.2 (1.0 to 1.5$)$ \\
\hline Unmarried & $52(10.9)$ & $39(75.0)$ & 1.4 (1.1 to 1.9$)$ & 1.3 (0.8 to 2.0$)$ \\
\hline Widow/separated & 58 (12.2) & $31(53.5)$ & 1 & 1 \\
\hline
\end{tabular}

${ }^{*}$ Column percentage.

†Row percentage.

¥Cluster adjusted (ART centres) generalised linear (Poisson) model; those categories (except 'not recorded' and 'others') with lowest proportion of IPT non-initiation were considered as reference categories in the model.

$\S A$ ble to read and write but no formal education.

ART, antiretroviral therapy; IPT, isoniazid preventive therapy; PLHIV, people living with HIV; RR, relative risk.

define IPT coverage. The IPT initiation rate within 3 months of eligibility provides a better monitoring indicator which covers both IPT coverage and timeliness of initiation of IPT. Consistent with the other studies, the IPT completion rates were high $(94 \%)$ in the current study. ${ }^{23-28}{ }^{36}{ }^{37}$ Hence, it can be reasoned that the hurdle for prevention of TB among PLHIV is low rate of IPT initiation.

Along with IPT coverage and completeness, some more programmatically relevant aspects were noted during this study. The 'ART register' was incomplete with details on education and occupation missing for more than half of the registered PLHIV. The CD4 count at registration, which is used to assess the immunological improvement and decide on the course of ART was not available in about one-third of the registered PLHIV. In contrast to incompleteness of documentation and low IPT coverage, the study setting had a high ART initiation rate (98\%), which was appreciable. This high ART initiation rate may be due to adoption of 'test and treat' strategy, improved efforts of the NCASC in procurement and supply of ART drugs, frequent training of all the NCASC and health staff regarding ART and use of ART initiation rate as an indicator to monitor the performance of ART centre. Lessons learnt in improving the ART coverage can be considered to improve the IPT coverage in study setting.

This study has a few strengths. First, this is the first study assessing the IPT coverage in the programme setting of resource limited Far-Western Region of Nepal. Second, there was no selection bias as all the PLHIV registered for care in the 11 ART centres of Far-Western Region were included. 
Table 3 Clinical factors associated with non-initiation of IPT among PLHIV registered between January 2016 and December 2017 in the Far-Western Region of Nepal, $n=477$

\begin{tabular}{|c|c|c|c|c|}
\hline Characteristic & Total, N (\%)* & $\begin{array}{l}\text { Not initiated on IPT, } \\
\mathrm{N}(\%) \dagger\end{array}$ & $\begin{array}{l}\text { Unadjusted RR } \\
(95 \% \mathrm{Cl})\end{array}$ & $\begin{array}{l}\text { Adjusted RR } \\
(95 \% \mathrm{Cl}) \ddagger\end{array}$ \\
\hline Total & $477(100)$ & $336(70.4)$ & & \\
\hline Less than 200 & $124(26.0)$ & $92(74.2)$ & 1.0 (0.9 to 1.3$)$ & 1.1 (0.9 to 1.3$)$ \\
\hline $200-350$ & $73(15.3)$ & $44(60.3)$ & $0.8(0.7$ to 1.1$)$ & $0.9(0.7$ to 1.1$)$ \\
\hline More than 500 & $69(14.7)$ & $49(71.0)$ & 1 & 1 \\
\hline Not recorded & $137(28.7)$ & $111(81.0)$ & 1.1 (1.0 to 1.4$)$ & 1.2 (0.9 to 1.6$)$ \\
\hline \multicolumn{5}{|l|}{ WHO clinical staging } \\
\hline | or || & $274(57.4)$ & 195 (71.2) & 1.0 (0.9 to 1.2$)$ & \\
\hline III or IV & $172(36.1)$ & $119(69.2)$ & 1 & \\
\hline Not initiated on ART & $11(2.3)$ & $11(100)$ & 1.5 (1.4 to 1.6$)$ & 1.4 (1.1 to 1.8$)$ \\
\hline
\end{tabular}

${ }^{*}$ Column percentage.

†Row percentage.

¥Cluster adjusted (ART centres) generalised linear (Poisson) model; those categories (except 'not recorded' and 'others') with lowest proportion of IPT non-initiation were considered as reference categories in the model.

ART, antiretroviral therapy; IPT, isoniazid preventive therapy; PLHIV, people living with HIV; RR, relative risk.

Third, about $10 \%$ data extraction forms were rechecked by the principal investigator for data quality. Fourth, data quality was assured as data was double entered and validated using EpiData software. Fifth, the Strengthening the Reporting of Observational Studies in Epidemiology checklist has been used for reporting this study.

This study has a few limitations. First, secondary data were used which had missing information on few sociodemographic details. Also, recording errors and incompleteness of documentation cannot be ruled out. Second, the proportion eligible for IPT might have been overestimated, as only all those PLHIV without active TB could be considered as eligible for IPT. However, we have conducted sensitivity analysis to derive the eligibility and initiation rate estimates adjusting for this overestimation. Third, the study was not powered to find association between baseline characteristics of PLHIV and initiation of IPT. Also, the model developed for assessing the independent effect of patient level characteristics on IPT initiation might be deficient as few important confounders like socioeconomic status, migration and adherence to ART could not be included in it. Fourth, completeness of IPT was assessed based on the receipt of IPT drugs during six consecutive visits and did not take into consideration the adherence to drugs.

Few recommendations can be put forth based on the findings of this study. First, there is need for carrying out clinical and laboratory examinations to assess the eligibility for IPT and document the details of the same in 'ART register'. The 'ART register' needs to be restructured with inclusion of appropriate columns (fields?) to document the details of assessment of IPT eligibility, which is currently not available. Second, the programme monitoring and supervision needs to be strengthened and special emphasis needs to be given on completeness of records. Third, the programme managers need to explore the possible reasons for low initiation rates of IPT using qualitative research methods and take corrective actions based on those findings. Fourth, cohortbased IPT initiation rate can be added as an indicator in the quarterly reporting formats of ART centre and also used for monitoring the programme implementation.

\section{CONCLUSION}

In FWR of Nepal, about three out of 10 eligible PLHIV are receiving IPT. Among those who have received IPT, the completion rate was good. The HIV care programme needs to explore the potential reasons for this low coverage and take context-specific corrective action to fix this gap.

\section{Author affiliations}

${ }^{1}$ Faculty of Science and Technology, Far Western University, Mahendranagar, Nepal ${ }^{2}$ Centre for Operational Research, International Union Against Tuberculosis and Lung Disease, Paris, France

${ }^{3}$ Centre for Operational Research, The Union South-East Asia Office, New Delhi, India

${ }^{4}$ Department of Preventive and Social Medicine, Jawaharlal Institute of Postgraduate Medical Education and Research (JIPMER), Puducherry, India ${ }^{5}$ National Center for AIDS and STD Control, Kathmandu, Nepal

${ }^{6}$ Sukraraj Tropical and Infectious Disease Hospital, Kathmandu, Nepal ${ }^{7}$ International Centre for Reproductive Health (ICRH), Department of Public Health and Primary Care, Faculty of Medicine and Health Sciences, Ghent University, Gent, Belgium 
${ }^{8}$ Research Laboratory for Human Reproduction, Faculty of Medicine, School of Public Health, Université Libre de Bruxelles (ULB), Bruxelles, Belgium

Acknowledgements This research was conducted through the Structured Operational Research and Training Initiative (SORT IT), a global partnership led by the Special Program for Research and Training in Tropical Diseases at the WHO. The model is based on a course developed jointly by the International Union Against Tuberculosis and Lung Disease (The Union) and Medécins sans Frontières (MSF/ Doctors Without Borders). The specific SORT IT programme which resulted in this publication was jointly developed and implemented by The Union South-East Asia Office, New Delhi, India; the Center for Operational Research, The Union, Paris, France; The Union, Mandalay, Myanmar; The Union, Harare, Zimbabwe; MSF Luxembourg Operational Research; MSF Operational Center Brussels; Jawaharlal Institute of Postgraduate Medical Education and Research, Puducherry, India; Velammal Medical College Hospital and Research Institute, Madurai, India; National Center for Tuberculosis Control and Prevention, China Centre for Disease Control, Beijing, China and Khesar Gyalpo University Medical Sciences of Bhutan, Thimpu, Bhutan. We would also express sincere thanks to antiretroviral therapy (ART) in-charges, counsellors and peer educators of all the 11 ART centres, as well as data collectors for their support during data collection.

Contributors GPD was the principal investigator; PT and PC were the SORT IT course mentors; BP and WHZ are the senior authors. GPD and UB were involved in data collection; GPD, PT and PC analysed the data and prepared the first draft of paper. All authors were involved in conception, design, inference of results, providing critical review to the manuscript and approval of the manuscript from this protocol.

Funding The AIDS Healthcare Foundation (USA) provided research grants to completely cover the expenses incurred during data collection. The SORT IT training program, within which this paper was developed, and the open access publication costs were funded by the Department for International Development, UK and La Fondation Veuve Emile Metz-Tesch (Luxembourg). The funders had no role in study design, data collection and analysis, decision to publish or preparation of the manuscript.

Disclaimer The depiction of boundaries on the map(s) in this article do not imply the expression of any opinion whatsoever on the part of BMJ (or any member of its group) concerning the legal status of any country, territory, jurisdiction or area or of its authorities. The map(s) are provided without any warranty of any kind, either express or implied.

Competing interests None declared.

Patient consent for publication Not required.

Ethics approval Ethical approval was obtained from the Ethics Advisory Group of the International Union Against Tuberculosis and Lung Disease, Paris, France (EAG number: 19/18), and this study was conducted as a part of a bigger project which had been approved by Far-Western University Faculty of Science and Technology. Written permission was obtained from Director, National Centre for AIDS and Sexually Transmitted Disease Control for extracting the routine data collected at ART centres.

Provenance and peer review Not commissioned; externally peer reviewed.

Data sharing statement Technical appendix, statistical code, and dataset available from the https://www.dropbox.com/sh/uxmdiz8vr1g7rgr/AAA3JTI_ hXUb0rsD1v6e3gbba?dl=0

Open access This is an open access article distributed in accordance with the Creative Commons Attribution Non Commercial (CC BY-NC 4.0) license, which permits others to distribute, remix, adapt, build upon this work non-commercially, and license their derivative works on different terms, provided the original work is properly cited, appropriate credit is given, any changes made indicated, and the use is non-commercial. See: http://creativecommons.org/licenses/by-nc/4.0/.

\section{REFERENCES}

1. World Health Organization. Global Tuberculosis Report 2018. Geneva, Switzerland, 2018:1-231.

2. Joint United Nations Programme on HIV/AIDS. Global HIV \& AIDS statistics - 2018 fact sheet. 2018 http://www.unaids.org/en/ resources/fact-sheet (Cited 6 Sep 2018)

3. World Health Organization. Consolidated guidelines on the use of antiretroviral drugs for treating and preventing HIV infection: recommendations for a public health approach. 2nd edn. Geneva, Switzerland, 2016.

4. World Health Organization. WHO policy on collaborative TB/HIV activities-Guidelines for national programmes and other stakeholders. Geneva, Switzerland, 2012.

5. World Health Organization. Latent tuberculosis infection: Updated and consolidated guidelines for programmatic management. Geneva, Switzerland, 2018.

6. Danel C, Moh R, Gabillard D, et al. A Trial of Early Antiretrovirals and Isoniazid Preventive Therapy in Africa. N Engl J Med 2015;373:808-22.

7. Lundgren JD, Babiker AG, Gordin F, et al. Initiation of Antiretroviral Therapy in Early Asymptomatic HIV Infection. N Engl J Med 2015;373:795-807.

8. Kanyerere H, Girma B, Mpunga J, et al. Scale-up of ART in Malawi has reduced case notification rates in HIV-positive and HIV-negative tuberculosis. Public Health Action 2016;6:247-51.

9. Kanyerere $\mathrm{H}$, Harries AD, Tayler-Smith $\mathrm{K}$, et al. The rise and fall of tuberculosis in Malawi: associations with HIV infection and antiretroviral therapy. Trop Med Int Health 2016;21:101-7.

10. Takarinda KC, Harries AD, Sandy C, et al. Declining tuberculosis case notification rates with the scale-up of antiretroviral therapy in Zimbabwe. Public Health Action 2016;6:164-8.

11. Yuen $\mathrm{CM}$, Weyenga $\mathrm{HO}, \mathrm{Kim} \mathrm{AA}$, et al. Comparison of trends in tuberculosis incidence among adults living with HIV and adults without HIV--Kenya, 1998-2012. PLoS One 2014;9:e99880.

12. Gupta RK, Rice B, Brown AE, et al. Does antiretroviral therapy reduce HIV-associated tuberculosis incidence to background rates? A national observational cohort study from England, Wales, and Northern Ireland. Lancet HIV 2015;2:e243-51.

13. Gupta A, Wood R, Kaplan R, et al. Tuberculosis incidence rates during 8 years of follow-up of an antiretroviral treatment cohort in South Africa: comparison with rates in the community. PLoS One 2012; 7:e34156

14. Akolo C, Adetifa I, Shepperd S, et al. Treatment of latent tuberculosis infection in HIV infected persons. Cochrane Database Syst Rev 2010;1:CD000171.

15. Charan J, Goyal JP, Reljic T, et al. Isoniazid for the Prevention of Tuberculosis in HIV-Infected Children. Pediatr Infect Dis J 2018;37:773-80.

16. Zunza M, Gray DM, Young T, et al. Isoniazid for preventing tuberculosis in HIV-infected children. Cochrane Database Syst Rev 2017;8:CD006418.

17. Golub JE, Pronyk P, Mohapi L, et al. Isoniazid preventive therapy, HAART and tuberculosis risk in HIV-infected adults in South Africa: a prospective cohort. AIDS 2009;23:631-6.

18. Golub JE, Saraceni V, Cavalcante SC, et al. The impact of antiretroviral therapy and isoniazid preventive therapy on tuberculosis incidence in HIV-infected patients in Rio de Janeiro, Brazil. AIDS 2007;21:1441-8

19. Badje A, Moh R, Gabillard D, et al. Effect of isoniazid preventive therapy on risk of death in west African, HIV-infected adults with high CD4 cell counts: long-term follow-up of the Temprano ANRS 12136 trial. Lancet Glob Health 2017;5:e1080-9.

20. Yirdaw KD, Jerene D, Gashu Z, et al. Beneficial effect of isoniazid preventive therapy and antiretroviral therapy on the incidence of tuberculosis in people living with HIV in Ethiopia. PLoS One 2014;9:e104557.

21. Rangaka MX, Wilkinson RJ, Boulle A, et al. Isoniazid plus antiretroviral therapy to prevent tuberculosis: a randomised doubleblind, placebo-controlled trial. Lancet 2014;384:682-90.

22. World Health Organization. Interim Policy on Collaborative TB/HIV Activities. Geneva, Switzerland, 2004.

23. Ayele AA, Asrade Atnafie S, Balcha DD, et al. Self-reported adherence and associated factors to isoniazid preventive therapy for latent tuberculosis among people living with HIV/AIDS at health centers in Gondar town, North West Ethiopia. Patient Prefer Adherence 2017;11:743-9.

24. Ayele HT, van Mourik MS, Bonten MJ. Predictors of adherence to isoniazid preventive therapy in people living with HIV in Ethiopia. Int $J$ Tuberc Lung Dis 2016;20:1342-7.

25. Little KM, Khundi M, Barnes GL, et al. Predictors of isoniazid preventive therapy completion among adults newly diagnosed with HIV in rural Malawi. Int J Tuberc Lung Dis 2018;22:371-7.

26. Takarinda KC, Choto RC, Harries AD, et al. Routine implementation of isoniazid preventive therapy in HIV-infected patients in seven pilot sites in Zimbabwe. Public Health Action 2017;7:55-60.

27. Sah SK, Sahu SK, Lamichhane B, et al. Dotting the Three I's for collaborative TB-HIV activities: evaluation of a pilot programme in Kathmandu, Nepal. Public Health Action 2016;6:169-75. 
28. Ousley J, Soe KP, Kyaw NTT, et al. IPT during HIV treatment in Myanmar: high rates of coverage, completion and drug adherence. Public Health Action 2018;8:20-4.

29. Ministry of Health \& Population, Department of Health Services, National Tuberculosis Centre. National Tuberculosis Program Nepal Annual Report-2017 [Internet]. Thimi, Bhaktapur. 2018.

30. Sah SK, Verma SC, Bhattarai R, et al. Surveillance of HIV Infection among Patients with Tuberculosis in Nepal. SAARC Journal of Tuberculosis, Lung Diseases and HIVIAIDS 2016;12:25-30.

31. Department of International Development. Regional Dimensions of Poverty and Vulnerability in Nepal. 2013 https://assets.publishing. service.gov.uk/government/uploads/system/uploads/attachment data/file/209483/Regional-dimension-poverty-nepal-background.pdf

32. Central Bureau of Statistics. National population and housing census 2011. Vol. 1 [Internet]. Kathmandu, Nepal. 2012 https://unstats.un. org/unsd/demographic/sources/census/wphc/Nepal/Nepal-Census2011-Vol1.pdf.
33. Ministry of Health, New ERA, The DHS Program. Nepal Demographic and Health Survey 2016 [Internet]. Kathmandu, Nepal. 2017 https:// dhsprogram.com/pubs/pdf/FR336/FR336.pdf.

34. Vaidya NK, Wu J. HIV epidemic in Far-Western Nepal: effect of seasonal labor migration to India. BMC Public Health 2011;11:310.

35. National Centre for AIDS and STD Control. National HIV Testing and Treatment Guidelines 2017, Kathmandu, Nepal. 2017 https://www. aidsdatahub.org/sites/default/files/toolandguide/document/National_ HIV_testing_and_Treatment_Guidelines_2017.pdf.

36. Trinh TT, Han DT, Bloss E, et al. Implementation and evaluation of an isoniazid preventive therapy pilot program among HIV-infected patients in Vietnam, 2008-2010. Trans R Soc Trop Med Hyg 2015;109:653-9.

37. World Health Organization. Global Tuberculosis Report 2017. Geneva, Switzerland, 2017. 